\title{
Varicocele and male infertility. Reproduction prognosis of the surgical treatment
}

\begin{abstract}
Varicocele ranks first among the causes of male infertility (MI). However, the severity of spermatogenic insufficiency when you can consider the results of varicocelectomy operation to be efficient is not still clear nowadays. The problem of the testicular insufficiency in case of varicocele is explained not only by unfavourable hemodynamic influence on the testicular function. It is related to the aspects of embryogenesis disturbance, as well. Hypogonodism, associated with varicocele in MI syndrome, has a polygenetic nature, and due to this pathogenous mechanisms of reproduction injury in males have variability. In 40 patients with MI and left-sided orthostatic varicocele the clinical manifestation of hypogonadism has been found out in combination with the symptoms of the connective tissue displasia syndrome (CTDS). The study has revealed the heterogenicity of the testicular insufficiency in patients with MI and varicocele that proves the necessity of the multidisciplinary approach in the etiopathogenetic diagnostics of the reproductive disturbances and the andrological syndrome in case of varicocele, including the reproductive prognosis of the surgical treatment.
\end{abstract}

Keywords: ricocele, sterile marriage, male infertility, hypogonadism, connective tissue displasia syndrome, abnormality of development, andrologic status
Volume 4 Issue 2 - 2018

\author{
Zhiborev BN \\ Ryazan Acad. I.P. Pavlov State Medical University of Ministry of \\ Public Health, Russia
}

\begin{abstract}
Correspondence: Zhiborev BN, Ryazan Acad. I.P. Pavlov State Medical University of Ministry of Public Health, Russia,
\end{abstract} Email zhbn47@mail.ru

Received: January 27, 2018 | Published: April II, 2018

\section{Introduction}

The clinical practice shows that the relations between MI and wide-spread surgical diseases of the genital system are cause and effect of it. In particular, in case of the left orthostatic varicocele the generative function in $50 \%$ of males remains preserved, it indicates the different andrological status of those patients, and does not exclude the presence of various pathogenetic mechanisms of formation of the testicular insufficiency in them. ${ }^{1-4}$

Varicocele treatment is a controversial problem. The methods of the surgical correction of the minor development anomaly (MDA) continue to improve nowadays. Meanwhile, the andrologic purpose of the surgery often becomes of lesser importance. ${ }^{5}$ The andrologic syndrome diagnosis is complicated due to the following: male hypogonadism as congenital development abnormality (CDA) can have minor symptoms: the external conformity of the testicle to the phenotype does not exclude displasticity of its structure. ${ }^{6}$ In the latest reports the researchers have paid attention to non-stable level of gonadotrophic hormones in the blood of patients with varicocele. ${ }^{7-10}$ It increases causes of sub infertility of these patients.

Practicing clinicists, dealing with the surgical treatment of diseases of scrotum and groin area, evaluate hypogonadism and improper development of gonads not to the full as they have other tasks to solve. In this situation the question about reproduction prognosis remains uncertain. ${ }^{11-13}$

Having the aim to clarify the etiology of the testicular insufficiency in patients with varicocele and for finding out the causes for the negative prognosis of restoration of the reproductive function after the surgical correction of varicocele we have performed the present study.

\section{Objects and methods of investigation}

We have investigated and treated 40 sub infertile males with the left-sided orthostatic varicocele. They have been in sterile marriage for 1.5-5.5 years (on average, $3.46 \pm 0.28$ years). In all patients 46 , XY karyotype has been diagnosed. For all patients we have applied bandages and transected the internal seminal vein according to Ivanissevich. The average age of patients at the moment of surgery was $26.9 \pm 0.47$ years. Varicocele is considered to be clinically significant if the diameter of the inner seminal vein exceeds $0.35 \mathrm{~cm}$, that is determined by the method of ultrasonic colour Doppler. ${ }^{14}$ The anamnesis is studied with the data of physical investigation of patients taking into consideration the sexual type and manifestation of connective tissue displasia syndrome (CTDS). The basal levels of luteinizing hormone ( $\mathrm{LH})$, follicle stimulating hormone (FSH), testesteron ( $\mathrm{t}$ ), estradiol (e), prolactin (PSR) in blood plasma have been studied. Excretion of the general neutral 17-CS and phosphotase index (FI) for normandrogenemia control have been evaluated. ${ }^{15}$

Further results of restoration of reproductive function after varicocele have been controlled in 34 couples. On average, the process of follow-up of patients after varicocele has been $2.4 \pm 0.54$ years (0.5-8 years). Spermagram and exprimates of the genital system have been investigated in dynamics in accordance with the criteria of the WHO (1999), and while evaluating the morphology of sexual cells we have calculated the fertility index (FI): the ratio of the morphological non-changed kinds to the number of the pathological ones. $^{2}$ In case, if the ratio is $50 \%$ of normal spermatozoon to $50 \%$ of changed spermatozoon, FI is 1.0- it is the threshold of fertility. If there is an indication, we perform the open biopsy of testicles. The criterion to exclude a patient from the experiment is the disturbance of female infertility according to the conclusion of a gynecologist.

\section{Results and discussion}

Varicocele, stage I, has been diagnosed in 7 patients $(17.5 \%)$, in 22 patients -stage II (53\%), and in 11 patients (27.5\%)-stage III. The improvement of the semen quality during the first year after 
the operation has been noted in $75 \%$ of patients. In 34 couples, investigated within more than 3 years after the surgery, the pregnancy has been registered in 55\% of cases. On average, there have been 19 conceptions in each group. Deliveries have taken place in 16 couples; it is $47.06 \%$ of cases. All babies have been born alive. In one case pregnancy has been reported 13 months later after the varicocelectomy - the couple has been followed-up and treated.

We have assessed the andrology status and male testicular insufficiency in 2 groups that have been formed on the basis of pregnancy in sterile marriage after varicocelectomy: the group A-19 males with the restored fertility, and the group B-15 males resistant to the effect of varicocelectomy. The fact of absence of restoration of the fertility in the married couple after varicocelectomy indicates the expressed manifestations of hypogonadism in patients (the group B). Morphometry of the gonads confirms the significant deviations in the andrological status of patients with varicocele and infertility in the number of resistant patients to the effect of varicocelectomy.

It is known that the anatomical dimensions of the testicle correlate with its function. The testicle volume of $15 \mathrm{~cm}^{3}$ has a normal spermatogenesis in more than $95 \%$ of cases. ${ }^{16}$ The results of orhidometry in all patients with infertility and varicocele (groups A and $\mathrm{B}$ ) show that the difference of average volumes of the right and left testicles in these patients is $3.0 \mathrm{~cm}^{3}(\mathrm{p}<0.05)$ in the whole of the population. Thus, the volume of the right testicle prevails over the left one $\left(\mathrm{M}\right.$ of the right testicle $=16,87 \pm 0.95 \mathrm{~cm}^{3}$ and $\mathrm{M}$ of the left testicle $=13.87 \pm 0.68 \mathrm{~cm}^{3}$ ).
Hypoplasia (or hypotrophy) of the gonads in patients with varicocele has a relation to the fact of restoration of the reproductive function in patients after varicocelectomy. Thus, the average amount of the total volume of gonads ( $\mathrm{V}$ of the right testicle $+\mathrm{V}$ of the left one) in the patient of the group with the effect of fertilization (group A) has been equal to $37.79 \pm 1.83 \mathrm{~cm}^{3}$ (with the phenotypic indicator $30.0 \mathrm{~cm} 3$ ). In the group of patients, resistant to the effect of varicocelectomy, the average value of this indicator has been $8.09 \mathrm{~cm} 3$ less and have been $29.7 \pm 3.4 \mathrm{~cm}^{3}$. The difference of average values is significant and $0.01>p>0.001$. It means that in patients of the group B the volume of the left testicle is less than that of the right testicle. It is typical for the testicular insufficiency, including hypogonadism and the congenital malformations $(\mathrm{CM})$.

The assumption of presence of the systemic malformations, including sexual glands in the andrological status of patients with infertility and varicocele is found out in the prevalence of CM, as well as it is associated with the violation of mechanism of hereditary factors. The total number of $\mathrm{CM}$ of the urinary system, the minor anomalies of development (MAD) of the skull, of the bone and joint system and the manifestations of connective tissue displasia syndrome (CTDS).

The number of congenital malformations (CM) and minor anomalies of development (MAD) in mentioned above localizations in Table 1 in recalculation for one patient is equal to: 1.05 ; 1.05 ; $2.08 ; 1.44 ; 2.08$. So, in one patient with the infertility and varicocele almost 7.7 symptoms have been diagnosed having dysembryogenetic properties, making the sexual type even worse.

Table I The number of congenital malformation (CM) and minor anomalies of development (MAD) in the examined patients with varicocele ( $n=39$ )

\begin{tabular}{|c|c|c|c|c|}
\hline № & $\begin{array}{l}\text { Area of } \\
\text { Manifestation }\end{array}$ & $\begin{array}{l}\text { Total } \\
\text { number }\end{array}$ & Frequently encountered $C M$ and MAD & $\begin{array}{l}\text { Frequency } \\
\text { indicator }\end{array}$ \\
\hline I & $\begin{array}{l}\text { CM of urinary } \\
\text { system }\end{array}$ & 41 & $\begin{array}{l}\text { Ureterocele, hydronephrosis, nephroptosis, changes of function of } \\
\text { the renal tubules }\end{array}$ & $13,7 \%$ \\
\hline 2 & CM of sexual system & 41 & $\begin{array}{l}\text { Hypoplasia, congenital phimosis, ectopy of the testicle, scrotal } \\
\text { dysmorphism, dysplasia of penis cavernous body }\end{array}$ & $13,7 \%$ \\
\hline 3 & $\begin{array}{l}\text { CM of facial and } \\
\text { brain skull }\end{array}$ & 81 & $\begin{array}{l}\text { Epicant, dental dysmorphism, disbalance of major segments of the } \\
\text { face, microstomy, geographical language, etc. }\end{array}$ & $27 \%$ \\
\hline 4 & $\begin{array}{l}\text { CM of bone and } \\
\text { joint system }\end{array}$ & 56 & $\begin{array}{l}\text { Early period of development (interval), scoliosis spina bifida sacralis, } \\
\text { clinodactyly, etc. }\end{array}$ & $18,7 \%$ \\
\hline 5 & $\begin{array}{l}\text { Anomalies of other } \\
\text { body systems }\end{array}$ & 81 & $\begin{array}{l}\text { Congenital pathology of the organs of vision, the Gilbert syndrome, } \\
\text { the varicose of veins of the lower limbs, the prolapse of the mitral } \\
\text { valve, the additional breast nipple, etc. }\end{array}$ & $27 \%$ \\
\hline
\end{tabular}

The revealed anomalies of various organs and systems testify the changes in the process of mutation in a patient with varicocele and gives the possibility to consider varicocele to be an anomaly, most often associated with the minor anomalies of development (MAD) of kidneys, congenital malformations $(\mathrm{CM})$ of the bone and joint system, testicular insufficiency, other genital malformations.

The identified hypoplasia of the gonads, pathospermy, and the symptoms of dysplastic syndrome gives the possibility to think of patients with varicocele of having disgenesis of the gonads as the form of congenital malformation (CM), that in symptomocomplex with the anomaly of the internal seminal vein enhance the "andrologic" symptoms of varicocele. In such cases, varicocele as the main cause of male infertility cannot be convincingly proved, and finding of extended internal seminal vein in a patient with the reproduction disorders can only be perceived as a possible version of the etiology of male infertility (MI).
Evaluation of the hormonal status in the examined patients indicates the heterogenecity of the testicular deficiency, hypogonadism in the compared groups. In patients with the effect of fertilization (the group A) the initial level of total testosterone of the blood plasma is equal to the average physiological level $(26.3 \pm 4.77 \mathrm{nmol} \mid \mathrm{L})$, and in the comparison group tends to the minimum value $(12.42 \pm 2.47$ nmol|L) with the probability of $90 \%$. The concentration of the follicle hormone (FSH) in patients of the group B (with unrestored fertility) exceeds that in patients from the group A-3.73 IU $\mid \mathrm{L}(\mathrm{p}<0.010)$. The primary hypergonadotropic hypogonadism among the patients, resistant to treatment, has been discovered by us at the rate of $50 \%$. Hyperprolactinemic hypogonadism has been detected in $18 \%$ of patients with male infertility (MI) and varicocele. The diagnosed versions of hypogonadism have a competitive value in etiology of male infertility (MI) alongside with the negative influence of varicocele that makes the andrological syndrome worse. 
In comparison of groups the process of catabolism of sexual steroids is not the same. In patients with the effect of fertilization IF index has a poor correlation with the level of allocation of the common $17-\mathrm{KS}(\mathrm{p}=-0.29)$. In the group with the negative reproduction results (the group B) the negative correlation of a strong degree $(p=-0.85)$ is found out. The findings indicate that the unsound spermatogenic (excretory) and endocrine functions of gonads are more clearly seen in patients with varicocele, resistant to infertility recovery.

The polygenous nature of hypogonadism is also demonstrated by the histological results. The severe damage of the spermatic cord as a syndrome "only Sertoli cells" (OSC) is found out in $22.2 \%$ of cases. Less severe forms-focal OSC - are found out in the biological material in $39 \%$ of cases in patients with un restored reproductive function (the group B).

Thus, in patients with the restored fertility the testicular dysfunction has very often a secondary origin. Hypogonadism in this case is the consequence of the vicious venous drainage, not varicocele. Symptomocomplex (infertility+varicocele) in this case presents the so-called pathogenetic syndrome. In this group of patients the hypogonadism symptoms are reversible in case of etiotropic (including surgery) treatment. On the contrary, in a patient with nonrestored fertility hypogonadism manifestation indicates the severe testicular insufficiency developing like connective tissue displasia syndrome (CTDS).

\section{Conclusion}

The absence of the systemic approach in diagnostics of hypogonadism and disbalance of sexual hormones in the method of the genetic screening conceals the real existing variety of pathogenetic mechanisms, responsible for the development of the generative disorders in patients with varicocele. This circumstance contradicts the principles based on the etiopathogenetic approach while diagnosing and treating generative disorders in males in genital sphere by means of surgery. The modern approaches related to the clinical diagnostics of hypogonadism and andrologic status of patients with varicocele should be a leading problem in the standards of examination of children, teenagers and males of the reproductive age while preparing them for surgery.

The current problem of varicocelectomy-discovering of an extended vein-should be important. Patients with this pathology need a comprehensive examination, because their latent congenital malformation can cause much danger to their health. In preventive varicocelectomy ultrasonic Doppler with assessing of venotesticular reflux should be a standard for diagnosis of the disease. In the group of patients the detection of reflux gives a possibility not to be mistaken and prevent causing injury to a patient taking into consideration their andrologic status.

\section{Acknowledgements}

The author is grateful for approving, supporting and promotion of this scientific research to my consultant, academician of the
Russian Academy of Medical Sciences, Professor O.B. Loran, MD and Professor Y.B. Kirillov, MD. The specifically thank to the administration of I.P. Pavlov Ryazan State Medical University.

\section{Conflict of interest}

There is no conflict of interests while writing and submitting the article for publication.

\section{References}

1. Glybochko PV, Aljaev JuG, Chalyj ME, et al. New tendencies in diagnostics and treatment of patozoospermii after operative treatment of Varicocele. Clinical Nephrology. 2013;1:76-77.

2. Zhiborev BN. About rational approach to varicocele in the aspect of correction of reproductive function of the man. Articles and lectures of the V Congress “Men's Health”. Kislovodsk; 2009:442-447.

3. Dohle GR, Weidner W, Jungwirth. European Ass of Urology. Guidelines on Male Infertility. EAU; 2006:64.

4. Shleger PN, Margreiter M. Surgery for male infertility. EBU Update series. 2007;5(3):105-112.

5. Gudkov AV. Vascular anastomosis at varicocele. Materials of the 14th Congress of the Russian Society of Urologists. Saratov; 2014:403.

6. Savchenko NE, Kravcova GI. Congenital defects in the development of the genital system. In: Lazjuk GI, editor. Human Pathology: a Guide for physicians. Moscow; 1991:310-320.

7. Jacyk SP. Diseases of the organs of the reproductive sphere in boys and young men. In: Baranov AA, editor. The union of pediatricians of Russia. Scientific Children's Health Center. Moscow; 2013:100.

8. Gamidov SI, et al. Modern aspects of pathogenesis, diagnosis and treatment of male infertility. Kremlin medicine. 2009;2:26-30.

9. Dreval' AV. Endocrine diseases of male genital organs. Andrology and genital surgery. 2001;4:20-23.

10. Dohle GR, Weidner W, Jungwirth A, et al. Genetic Disorders in Infertility. Guidelines on male Infertility. EAU; 2004:18-25.

11. Akramov NR, Nazmeev RN, Matar AA. Diagnosis and treatment of boys with Varicocele syndrome in outpatient conditions: educationalmethodical manual. Kazan; 2012:97.

12. Veretennikov SI, Shapkin JuG, Vihljancev ON. To the question of optimization of the tactics of patient management with Varicocele. In: Materials of Scientific. Reviews of All Russian Congress on andrology. Moscow; 2007:16.

13. Kazanskaja IV. Organization (concept) of assistance to children with urogenital pathology. Andrology and genital surgery. 2004;3:65-68.

14. Ledda A. Vascular andrology: Erectile dysfunction, priapism, Varicocele: trans. from English. Moscow; 2002:103-135.

15. Gorjunov VG, Zhiborev BN, Evdokimov VV. Causes and signs of male infertility. Ryazan; 1993:85.

16. Meuleman E. The infertile couple, urological aspects. Birmingham, UK; 2002:15-30 